\title{
Phosphate binders for the treatment of chronic kidney disease: role of iron oxyhydroxide
}

This article was published in the following Dove Press journal: International Journal of Nephrology and Renovascular Disease 2 February 2016

Number of times this article has been viewed

\section{Valeria Cernaro \\ Domenico Santoro \\ Antonio Lacquaniti \\ Giuseppe Costantino \\ Luca Visconti \\ Antoine Buemi \\ Michele Buemi}

Department of Clinical and Experimental Medicine, University of Messina, Messina, Italy

\section{Video abstract}

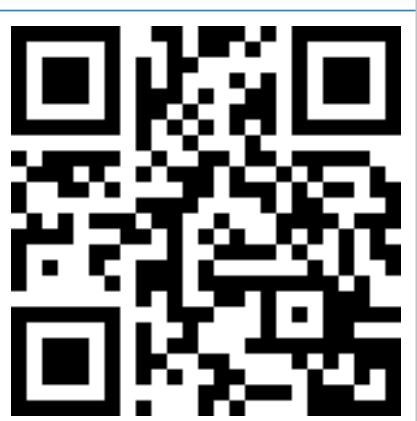

Point your SmartPhone at the code above. If you have a QR code reader the video abstract will appear. Or use: http://youtu.be/ZGw90GIUgsO
Correspondence: Valeria Cernaro Department of Clinical and Experimental Medicine, University of Messina, Via Consolare Valeria n I, 98124 Messina, Italy $\mathrm{Tel}+390902212396$

$\mathrm{Fax}+390902212329$

Email valecern82@virgilio.it
Abstract: Chronic kidney disease-mineral bone disorder is frequent in patients with renal failure. It is characterized by abnormalities in mineral and bone metabolism with resulting hyperphosphatemia, low serum vitamin $\mathrm{D}$, secondary hyperparathyroidism, altered bone morphology and strength, higher risk of bone fractures, and development of vascular or other soft tissue calcifications. Besides the recommendation to reduce phosphorus dietary intake, many drugs are currently available for the treatment of calcium/phosphate imbalance. Among them, phosphate binders represent a milestone. Calcium-based binders (calcium carbonate, calcium acetate) are effective in lowering serum phosphate, but their use has been associated with an increased risk of hypercalcemia and calcifications. Calcium-free binders (sevelamer hydrochloride, sevelamer carbonate, and lanthanum carbonate) are equally or slightly less effective than calcium-containing compounds. They would not induce an increase in calcium levels but may have relevant side effects, including gastrointestinal symptoms for sevelamer and risk of tissue accumulation for lanthanum. Accordingly, new phosphate binders are under investigation and some of them have already been approved. A promising option is sucroferric oxyhydroxide (Velphoro ${ }^{\circledR}$, PA21), an iron-based phosphate binder consisting of a mixture of polynuclear iron(III)-oxyhydroxide, sucrose, and starches. The present review is focused on pharmacology, mode of action, and pharmacokinetics of sucroferric oxyhydroxide, with a discussion on comparative efficacy, safety, and tolerability studies of this drug in chronic kidney disease and patient perspectives such as quality of life, satisfaction, and acceptability. Sucroferric oxyhydroxide has proven to be as effective as sevelamer in reducing phosphatemia with a similar safety profile and lower pill burden. Experimental and clinical studies have documented a minimal percentage of iron absorption without inducing toxicity. In conclusion, the overall benefit-risk balance of sucroferric oxyhydroxide is deemed to be positive, and this new drug may therefore represent a good alternative to traditional phosphate binders for the treatment of hyperphosphatemia in dialysis patients.

Keywords: chronic kidney disease-mineral bone disorder, CKD-MBD, iron(III)-oxyhydroxide, phosphate binders, sucroferric oxyhydroxide

\section{Introduction to the epidemiology and management issues in CKD}

Chronic kidney disease (CKD), defined by the presence of kidney damage and/or reduced function for a period greater than 3 months, is an increasingly relevant public health problem all over the world. According to a very recent systematic analysis, in 2010 the global prevalence of CKD in adults was $10.4 \%$ in men and $11.8 \%$ in women, with lower values in more developed countries and higher values in low- and middleincome countries. ${ }^{1}$ 
The incidence of the disease rises with age and it is expected to further increase with gradual population aging. ${ }^{2}$ Other major risk factors for reduced kidney function include: hyperuricemia, proteinuria, urinary malignancies, anemia, stroke, arterial hypertension, presence of renal cysts, female sex, smoking, and coronary artery disease..$^{3-5}$

Whereas in the past CKD was primarily a consequence of glomerulonephritis and interstitial nephritis, presently the leading causes of renal failure are diabetes mellitus and hypertension. ${ }^{6,7}$ In particular, it is estimated that the prevalence of diabetic CKD stage 5 in European countries will increase $3.2 \%$ per year up to 2025 . $^{8}$

CKD shows a natural tendency to evolve toward endstage renal disease, although this occurs with different times depending on the underlying etiology, and patients are burdened with a greater risk of comorbidities and mortality than general population, especially due to poor cardiovascular outcomes. Indeed, CKD patients frequently develop left ventricular hypertrophy, hypertension, valvular heart disease, left ventricular systolic failure, diastolic failure, arrhythmias, accelerated atherosclerosis progression, ischemic artery disease, and sudden cardiac death. ${ }^{9-13}$

Some therapeutic strategies, such as the blockage of reninangiotensin-aldosterone system, allow to slow down but not to fully halt CKD progression. For this reason, other potential treatments are currently under investigation but conclusive results are still lacking. ${ }^{14}$ Conversely, nephrologists are provided with validated medications to well enough control CKD complications including anemia, metabolic acidosis, hyperkalemia, and calcium/phosphate imbalance. Even so, researchers are ever looking for new treatment options in order to improve therapeutic effectiveness and solve important concerns regarding some adverse effects induced by the currently used drugs. An example is recombinant human erythropoietin that in the 80 s definitely revolutionized the treatment of anemia, previously requiring frequent blood transfusions. ${ }^{15}$ Despite the obvious benefits for the management of anemia due to CKD, some safety issues secondary to erythropoietin administration are still open and not easily resolvable. They are especially related to the risk for cancer progression, since erythropoietin acts as a cell growth factor, and to the potential unfavorable cardio- and cerebrovascular outcomes because of the increase in hematocrit, blood pressure, and thrombopoiesis. ${ }^{15-18}$

Focusing on calcium/phosphate metabolism, patients with progressive renal function impairment commonly develop the so-called CKD-mineral bone disorder (CKD-MBD), a syndrome characterized by abnormalities in mineral and bone metabolism with resulting altered bone morphology and strength, higher risk of bone fractures, and formation of vascular or other soft tissue calcifications. From a biochemical point of view calcium, phosphorus, parathyroid hormone, and vitamin D serum levels are often outside the physiological range. ${ }^{19,20}$

A significant role in the pathophysiology of CKD-MBD is also played by klotho and fibroblast growth factor 23 (FGF23). Klotho is a FGF23 tissue coreceptor and tends to decrease as renal function declines. ${ }^{21}$ This probably represents the first alteration to appear and also the factor responsible for progressive peripheral resistance to FGF $23,{ }^{22}$ a phosphaturic hormone produced by osteoblasts and osteocytes. As a result, FGF23 serum levels rise. At first, this is a compensatory mechanism aimed at inducing phosphaturia; however, with time FGF23 increase turns out to contribute to CKD-MBD pathogenesis because it inhibits $1 \alpha$-hydroxylase activity at the renal level so reducing 1,25-dihydroxyvitamin D3 expression. The consequences are the following: secondary hyperparathyroidism, altered phosphorus and calcium serum levels, increased bone remodeling, vascular calcifications, and further FGF23 production. ${ }^{23}$ Moreover, high FGF23 is an important risk factor for cardiovascular disease since it has been associated with left ventricular hypertrophy, activation of the renin-angiotensin system, increased sodium absorption in the renal distal tubules with subsequent sodium retention and volume expansion, increased markers of inflammation, and oxidative stress. ${ }^{24}$

The control of serum phosphate and FGF23 levels in CKD patients is therefore essential to preserve bone mineral content, prevent hyperparathyroidism, and reduce cardiovascular risk. It is noteworthy that not only food but also several drugs are a source of absorbable phosphate. ${ }^{25}$

\section{Outline of current and emerging treatment options for CKD with reference to phosphate binders}

Besides the recommendation to reduce the dietary intake of phosphorus, many drugs are currently available for the treatment of CKD-MBD; they include vitamin D sterols (calcitriol, cholecalciferol, ergocalciferol), active vitamin D analogs (paricalcitol, doxercalciferol, alfacalcidol), calcimimetics (cinacalcet), and phosphate binders. According to the purposes of this review, attention will be focused on the last class of medications.

Their mechanism of action is based on the binding of dietary phosphate within the gastrointestinal lumen to prevent its absorption. Depending on the presence or absence of calcium in their molecular structure, phosphate binders can be classified as calcium-based and calcium-free. ${ }^{23,26}$ 
Calcium-containing compounds (calcium carbonate, calcium acetate) have proven to be efficient in lowering serum phosphate concentrations. However, an increased risk of hypercalcemia, positive calcium balance, and development of vascular calcifications has been observed in patients receiving these drugs. ${ }^{27}$

Calcium-free binders (sevelamer hydrochloride, sevelamer carbonate, lanthanum carbonate) are equally or slightly less effective than calcium-based binders and their use does not seem to be associated with high calcium levels: this would reduce the risk for vascular calcifications. ${ }^{28-31}$ Nevertheless, calcium-free phosphate binders are also burdened with clinically significant side effects. Sevelamer carbonate may cause gastrointestinal adverse events including nausea, vomiting, dyspepsia, abdominal pain, and changes in bowel habits. ${ }^{32}$ Lanthanum carbonate appears to be well tolerated in the short to medium term except for a higher rate of vomiting, but there is the risk of lanthanum accumulation especially in bone and liver. Although some experimental and clinical studies suggest that lanthanum carbonate is fairly safe, large sample and long-term trials are required in order to assess the potential toxicity of lanthanum in the liver. ${ }^{33}$ Moreover, some authors have recently reported cases of lanthanum deposition in the gastric mucosa associated with peculiar histiocytic lesions, but their clinical significance needs to be clarified. ${ }^{34,35}$

Beyond the described side effects of both classes of phosphate binders, another relevant issue is the lack of placebo-controlled randomized clinical trials evaluating the impact of these drugs on hard endpoints such as death and cardiovascular outcomes. As a consequence, at present, the treatment of hyperphosphatemia is mostly driven by clinical experience and evaluation of the individual patient. ${ }^{36}$

Hence, even though numerous drugs are already in use in clinical practice, the "ideal" phosphate binder still does not exist. It should be effective in binding dietary phosphate with low pill burden, minimal gastrointestinal or other untoward effects, and no interaction with other medications; it should be also devoid of safety concerns and inexpensive; ${ }^{37}$ this is the reason why new phosphate binders have been approved over recent years and others are being investigated for the treatment of phosphate imbalance in CKD.

Among them is bixalomer, an amine functional polymer that was launched in Japan in June 2012 for the treatment of hyperphosphatemia in dialysis patients. Bixalomer seems to effectively reduce phosphatemia with fewer gastrointestinal symptoms compared to sevelamer hydrochloride ${ }^{38}$ Currently, approval for the extension of therapy to CKD patients not on dialysis is under evaluation, ${ }^{39}$ and two postmarketing clinical trials are ongoing to assess the safety and efficacy of longterm use of bixalomer in hemodialysis (NCT01901107) and in peritoneal dialysis patients (NCT01903213).

Another available therapeutic option is RenaGum ${ }^{\mathrm{TM}}$. This is a chewing gum formulated with chitosan, a natural linear polysaccharide able to bind salivary phosphate in the mouth and gastrointestinal tract. Actually, it must be regarded as a medical food to be taken together with phosphate binders and not as a replacement for these drugs, but it has proven to efficiently contribute to lower phosphatemia in CKD patients. ${ }^{40-42}$

A new category of phosphate binders is represented by iron-based compounds. They include drugs still under investigation such as iron-magnesium hydroxycarbonate or SBR759, ${ }^{37}$ and drugs already available such as ferric citrate hydrate or sucroferric oxyhydroxide ${ }^{43}$; the last one will be discussed in more detail in the next sections of this review. The presence of iron confers to these drugs the ability to bind phosphorus in the gastrointestinal lumen. Taking iron-based phosphate binders might be accompanied by an increase in serum iron, so patients suffering from important hepatic or gastric diseases or with a history of hemochromatosis or other disorders characterized by iron accumulation have not been included in clinical trials for the potential risk of iron overload. Lastly, non-iron-based binders are also under investigation. An example is Genz-644470, a polymer showing the ability to effectively reduce serum phosphate in hemodialysis patients but with no advantages over sevelamer carbonate. ${ }^{44}$

\section{Review of pharmacology, mode of action, and pharmacokinetics of iron oxyhydroxide}

Iron(III)-oxyhydroxide is the pharmacologically active part of a compound named sucroferric oxyhydroxide (Velphoro ${ }^{\circledR}$, PA21) and consisting of a mixture of polynuclear iron(III)oxyhydroxide, sucrose, and starches (Figure 1). ${ }^{45}$

This calcium-free iron-based phosphate binder was approved in the United States by the US Food and Drug Administration (FDA) in November 2013 $3^{46,47}$ and in Europe by the European Medicines Agency (EMA) in August 2014 for the treatment of hyperphosphatemia in CKD patients receiving dialysis.

The final product is a chewable tablet containing $500 \mathrm{mg}$ iron as polynuclear iron(III)-oxyhydroxide, sucrose, and starches, also known as sucroferric oxyhydroxide that is partially water-soluble. Digestion of sucrose results in the formation of glucose and fructose, while starch is digested to glucose and maltose. All obtained products are absorbed. Conversely, polynuclear iron(III)-oxyhydroxide is nearly 


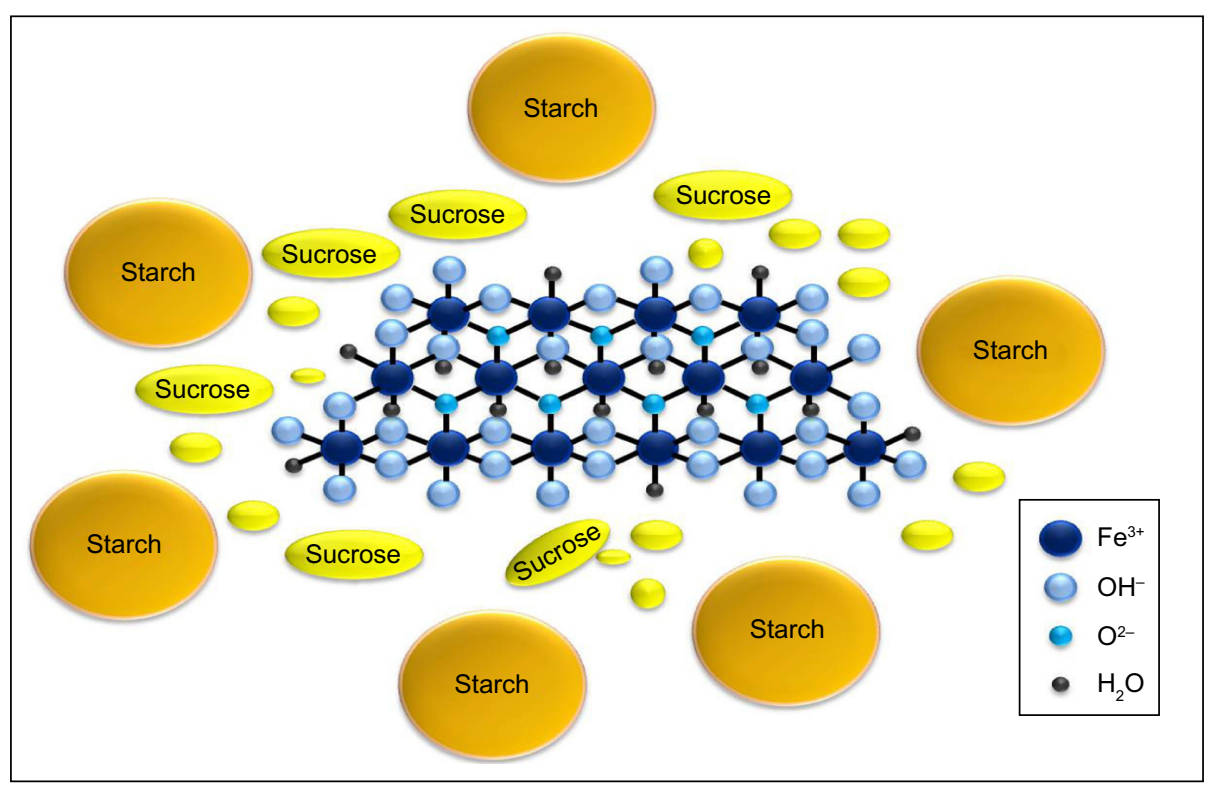

Figure I Molecular structure of sucroferric oxyhydroxide consisting of a mixture of polynuclear iron(III)-oxyhydroxide, sucrose, and starches. Note: Iron(III)-oxyhydroxide is the pharmacologically active part.

insoluble and this, although not completely, prevents iron being absorbed by the iron transporters of the duodenum. The function of sucrose molecules is to stabilize the iron, whereas starches help during the process of drug production. ${ }^{49,50}$

As for all iron-containing binders, the mechanism of action of sucroferric oxyhydroxide depends on the presence of iron. Experimental data suggest that the ability of this compound to bind phosphate is attributable to two different mechanisms. The first one is represented by the adsorption of phosphate to the iron complex. The second mechanism consists in the formation of iron phosphate through a chemical reaction that is favored by low $\mathrm{pH}$ values, such as those present within the stomach. In summary, the hypothesis is that the latter process basically occurs in the stomach whilst phosphate adsorption to the iron(III)-oxyhydroxide core happens in the intestinal lumen, both leading to the excretion of bound phosphate in the feces. ${ }^{49}$

Under experimental conditions reproducing administration of the drug on an empty stomach and full stomach across the physiological $\mathrm{pH}$ range, sucroferric oxyhydroxide demonstrated to efficiently bind phosphate at every $\mathrm{pH}$ value and release more iron at the lowest $\mathrm{pH}$ in the absence of phosphate, whereas the amount of iron freed resulted in being much lower when phosphate was present and minimal with $\mathrm{pH}$ ranging from 2.5 to $8.5 .{ }^{45}$ In more detail, in vitro experiments showed that iron release was equal to $0.3 \%$ at higher $\mathrm{pH}$ values while it amounted to a maximum of $6.3 \%$ at a $\mathrm{pH}$ of $1.2-1.5$; the last percentage went up to $67 \%$ using an artificial gastric juice without phosphate. ${ }^{49}$
It follows that iron uptake is greater in the fasting state and that, consequently, sucroferric oxyhydroxide must be taken with food.

In animal models treated with (59)Fe-radiolabeled sucroferric oxyhydroxide, iron absorption was proven to be low and long-term therapy only slightly increased tissue iron levels without inducing toxicity. ${ }^{51}$

With regard to excretion of the drug in preclinical studies, radioactivity was detected only in feces and not in bile or urine. ${ }^{49}$

A further important point is that CKD patients often have to take many medications throughout the day and this could expose them to the risk of drug interactions. Recent studies involving healthy volunteers have documented a low risk of drug-drug interactions between sucroferric oxyhydroxide and some drugs commonly used in dialysis patients including losartan, furosemide, digoxin, warfarin, and omeprazole. Then, their dosage does not need to be adjusted if sucroferric oxyhydroxide is simultaneously administered. ${ }^{52}$ However, a potential adsorption of levothyroxine by sucroferric oxyhydroxide has been reported; then, it is recommended that levothyroxine should not be prescribed with this phosphate binder. $^{49,53}$

\section{Comparative efficacy, safety, and tolerability studies of iron oxyhydroxide in CKD}

Over recent years, various clinical studies have been carried out to evaluate efficacy, safety, and tolerability of sucroferric 
oxyhydroxide compared to other phosphate binders commonly used in clinical practice.

Preliminary data on safety and efficacy of the drug were provided by Phase I studies. Some were conducted to evaluate the risk of drug-drug interactions in healthy volunteers. As mentioned before, the risk turned out to be low with losartan, furosemide, omeprazole, digoxin, and warfarin. ${ }^{52}$

Another Phase I study recruited patients with stage 3-4 $\mathrm{CKD}$, patients on hemodialysis, and healthy subjects. The aim was to evaluate the effects of 1-week treatment with sucroferric oxyhydroxide $10 \mathrm{~g}$ /day on serum phosphate concentrations and the potential risk for iron overload. Therapy induced a significant decrease in phosphatemia and the most common adverse event was mild-to-moderate diarrhea. Moreover, the administration of a single dose of radiolabeled compound demonstrated that iron uptake was low. ${ }^{54}$

Later, a Phase II, randomized, active-controlled, multicenter, open-label, dose-finding study (NCT00824460) was designed to evaluate efficacy and safety of different dosages of sucroferric oxyhydroxide $(1.25,5.0,7.5,10.0$, or 12.5 $\mathrm{g} /$ day) as compared to sevelamer hydrochloride ( $4.8 \mathrm{~g} /$ day) for 6 weeks in a cohort of 154 hemodialysis patients. Serum phosphate significantly decreased in all groups except that receiving sucroferric oxyhydroxide $1.25 \mathrm{~g} /$ day; in particular, the $5 \mathrm{~g}$ /day and $7.5 \mathrm{~g}$ /day dosages were as efficacious as $4.8 \mathrm{~g} /$ day of sevelamer hydrochloride. The adverse events that were more frequently reported included hypophosphatemia and discolored stools for all the sucroferric oxyhydroxide groups, and diarrhea, hypophosphatemia, and hypotension for sevelamer group. Their incidence and discontinuation rate owing to side effects were similar for both drugs.$^{55}$ These findings were subsequently confirmed by larger studies.

A multicenter, open-label, two-stage, prospective, randomized, parallel-group, active-controlled Phase III study (NCT01324128) ${ }^{56}$ compared sucroferric oxyhydroxide and sevelamer carbonate in a cohort of hemodialysis and peritoneal dialysis patients with hyperphosphatemia. Subjects were randomized to receive sucroferric oxyhydroxide 1.0-3.0 $\mathrm{g} /$ day $(\mathrm{n}=707)$ and sevelamer 4.8-14.4 g/day ( $\mathrm{n}=348)$ according to the following scheme of therapy: an 8 -week period for dose titration, 4 weeks without changing the doses, and a 12-week phase of maintenance treatment. After 12 weeks, serum phosphate similarly decreased in the two groups and the efficacy of both treatments was maintained comparable until week 24. It is noteworthy that this noninferiority was obtained with an average per day of 3.1 tablets of sucroferric oxyhydroxide and 8.1 of sevelamer calculated throughout the whole study. Moreover, for an additional 3-week period,
50 patients were treated with maintenance dose of sucroferric oxyhydroxide and 49 patients with a low dose of the same drug ( $250 \mathrm{mg} /$ day): serum phosphate control was achieved only with the maintenance dose. Nonadherence to therapy was lower for sucroferric oxyhydroxide than sevelamer. At least one adverse event was reported by $83.2 \%$ of patients treated with sucroferric oxyhydroxide and $76.1 \%$ of subjects receiving sevelamer, and withdrawals due to adverse events were higher in the first group than in the second one. Ferritin levels increased in both groups while transferrin saturation rose in patients treated with sucroferric oxyhydroxide. Such increases occurred early and then stabilized during the study period, suggesting no iron accumulation. Nevertheless, ferritin and transferrin saturation increases were greater in patients receiving sucroferric oxyhydroxide, indicating that minimal iron absorption cannot be excluded. The side effects more often observed in the sucroferric oxyhydroxide group were mild and transient diarrhea, discolored feces, and hyperphosphatemia; patients treated with sevelamer mainly experienced constipation and nausea. However, incidence of severe and serious adverse events and death was similar between the two treatment arms. This study concluded that sucroferric oxyhydroxide lowered serum phosphate in dialysis patients as effectively as sevelamer carbonate but with a lower pill burden and better adherence to therapy.

Afterwards, 644 eligible patients of this trial were enrolled for a 28-week open-label Phase III extension study (NCT01464190) $)^{57}$ during which they continued to receive the same treatment at the same dose as at the end of the first study ( $n=384$ sucroferric oxyhydroxide; $n=260$ sevelamer). The aim was to examine efficacy and tolerability of sucroferric oxyhydroxide in the long-term. The results confirmed those achieved in the initial study: indeed, sucroferric oxyhydroxide proved to efficiently reduce serum phosphate levels and this was associated with lower pill burden, good tolerability, and no evidence of iron accumulation.

Other clinical trials have been designed to investigate the effects of sucroferric oxyhydroxide in the long-term in hemodialysis (NCT01833494), peritoneal dialysis (NCT01852682), and associated with calcium carbonate in hemodialysis (NCT01850641). They have been completed but no results are yet available.

\section{Patient-focused perspectives such as quality of life and patient satisfaction/acceptability}

The clinical studies described in the previous section have revealed that therapy with sucroferric oxyhydroxide shows 
a safety profile that is similar to that of other calcium-free phosphate binders and requires a lower pill burden to achieve the same efficacy.

High number of pills is associated with poor healthrelated quality of life in chronic dialysis patients, and traditional phosphate binders represent approximately a half of their daily pill burden. ${ }^{58}$

As described in the European Medicines Agency Assessment report on Velphoro ${ }^{\circledR},{ }^{49}$ the authors of the NCT01324128 Phase III clinical trial ${ }^{56}$ included evaluation of quality of life (standard SF-36 questionnaire - Version 2.0) and patient preference and satisfaction (Likert scale) among the secondary objectives of the study.

Quality of life scores changed only slightly from baseline and no significant differences were recorded between sucroferric oxyhydroxide group and sevelamer group. Similarly, patient satisfaction for the current phosphate binder did not differ between the two arms of treatment as for number of pills, ease of intake, and overall satisfaction neither at baseline nor over time.

The reason for these results could be that pill burden is a relevant aspect to take into account in the management of chronic diseases because it affects adherence to therapies, but most likely it is not the major element in determining quality of life if compared to other factors, most notably the disease itself and the dialysis treatment in the specific case. However there is no doubt that a low pill burden increases acceptability of and compliance to the treatment. This helps drugs, including phosphate binders, to be effective thereby potentially reducing morbidity and mortality.

\section{Conclusion}

At present, nephrologists have the opportunity to treat CKDMBD by choosing from different drugs that allow controlling hyperphosphatemia in the late stages of renal failure. However, the therapeutic decision is generally based on an individual approach and probably the treatment is started too late compared to the earlier onset of calcium/phosphate imbalance in CKD. Furthermore, the current available drugs may not be as maximally effective as desirable and their use is often associated with high pill burden and side effects. All these factors definitely contribute to the still substantial cardiovascular morbidity and mortality attributable to increased phosphate and FGF23 serum levels in patients with renal impairment. Accordingly, these are also the reasons why researchers are looking for new phosphate binders that are expected to be not only effective but also more tolerated than those already in use in the clinical practice.
Iron-based non-calcium phosphate binders, such as sucroferric oxyhydroxide, may represent an interesting alternative to address and solve the issues described. Although comparative clinical studies with lanthanum carbonate are lacking, ${ }^{43}$ sucroferric oxyhydroxide has proven to be as effective as sevelamer with a similar rate of undesirable effects and the need for a lower number of pills.

Moreover, sucroferric oxyhydroxide was able to reduce serum phosphate and intact parathyroid hormone concentrations and prevent the development of vascular calcifications in a rat model of chronic renal failure as effectively as lanthanum carbonate and sevelamer carbonate. Sucroferric oxyhydroxide also induced a significant decrease in FGF23 levels. ${ }^{59}$ Iron itself seems to be involved in the regulation of FGF23 levels. In particular, iron status is an independent negative predictor of plasma FGF23 concentration and iron supplementation is associated with a significant decrease in FGF23 values. ${ }^{60}$ This is likely due to the role of iron and iron-related pathways in FGF23 synthesis and processing mechanisms. ${ }^{61}$ As a consequence of this regulatory action and the negative association between iron therapy and FGF23 serum levels documented in dialysis patients, ${ }^{62}$ iron administration per se and also treatment with iron-based phosphate binders may be helpful in the control of bone metabolism decreasing FGF23 both directly and by reducing phosphate intestinal absorption.

The most important concern arising from the clinical use of sucroferric oxyhydroxide regards the potential iron overload, especially in specific categories of patients. The chemical structure of sucroferric oxyhydroxide prevents iron absorption in the gastrointestinal tract, but experimental studies performed to evaluate pharmacokinetics have shown that a minimal percentage of iron is actually absorbed, even though without inducing toxicity. For this reason, patients with a recent episode of peritonitis, significant gastric or hepatic disease, and history of major gastrointestinal surgery, hemochromatosis, or other disorders with iron accumulation have not been included in clinical trials. It follows that close monitoring of iron homeostasis is mandatory when sucroferric oxyhydroxide is administered to these subjects. On the other hand, CKD patients often show iron deficiency ${ }^{63}$ and receive oral or intravenous iron supplementation. Several drug formulations are currently available, each of which is characterized by different iron content per pill (eg, ferrous gluconate: $300 \mathrm{mg}$, equivalent to $37.5 \mathrm{mg}$ of elemental iron; ferrous sulfate: $329.7 \mathrm{mg}$, corresponding to $105 \mathrm{mg}$ of elemental iron) and pharmacokinetic profile. Iron absorption occurring with sucroferric oxyhydroxide, which contains 
$500 \mathrm{mg}$ of iron as polynuclear iron(III)-oxyhydroxide in each tablet, could potentially reduce costs of anemia therapies, ${ }^{64}$ but this hypothetical advantage should be confirmed in long-term comparative efficacy studies with commonly used iron supplements.

Due to the presence of sucrose, the drug is contraindicated in the rare hereditary cases of fructose intolerance, glucose-galactose malabsorption, or sucrase-isomaltase insufficiency. Furthermore, discolored feces may mask eventual gastrointestinal bleeding and this is another issue that requires attention. ${ }^{49}$

Another major problem for the nephrologist is when to start treatment of hyperphosphatemia. As hypothesized for traditional phosphate binders, ${ }^{23}$ also iron-based binders may potentially be more effective in slowing down CKD-MBD progression if started earlier in stage 3-4 CKD. Indeed, phosphate appears not to be the ideal biomarker of calcium/phosphate imbalance since its serum levels are maintained within the normal range for a long time by the compensatory increase in parathyroid hormone and, even first, FGF23. Most likely, FGF23 itself might better drive clinical management of CKDMBD, but large trials are needed to standardize measurement methods and physiological values of this biomarker.

In conclusion, the overall benefit-risk balance of sucroferric oxyhydroxide is deemed to be positive because of the efficacy, safety profile, and only limited potential iron absorption. This iron-based phosphate binder may therefore represent a new good option for the treatment of hyperphosphatemia in CKD patients on dialysis.

\section{Disclosure}

The authors report no conflicts of interest in this work.

\section{References}

1. Mills KT, Xu Y, Zhang W, et al. A systematic analysis of worldwide population-based data on the global burden of chronic kidney disease in 2010. Kidney Int. 2015;88:950-957.

2. Buemi M, Lacquaniti A, Bolignano D, et al. Dialysis and the elderly: an underestimated problem. Kidney Blood Press Res. 2008;31(5):330-336.

3. Haroun MK, Jaar BG, Hoffman SC, Comstock GW, Klag MJ, Coresh J. Risk factors for chronic kidney disease: a prospective study of 23,534 men and women in Washington County, Maryland. J Am Soc Nephrol. 2003;14(11):2934-2941.

4. Liu W, Yu F, Wu Y, et al. A retrospective analysis of kidney function and risk factors by Chronic Kidney Disease Epidemiology Collaboration (CKD-EPI) equation in elderly Chinese patients. Ren Fail. 2015;37;1323-1328.

5. Lacquaniti A, Bolignano D, Campo S, et al. Malnutrition in the elderly patient on dialysis. Ren Fail. 2009;31(3):239-245.

6. Low SK, Sum CF, Yeoh LY, et al. Prevalence of chronic kidney disease in adults with type 2 diabetes mellitus. Ann Acad Med Singapore. 2015;45(5):164-171.
7. Thawornchaisit P, De Looze F, Reid CM, Seubsman SA, Tran TT, Sleigh A, Thai Cohort Study Team. Health-risk factors and the prevalence of chronic kidney disease: cross-sectional findings from a national cohort of 87143 Thai open university students. Glob J Health Sci. 2015;7(5):59-72.

8. Kainz A, Hronsky M, Stel VS, et al. Prediction of prevalence of chronic kidney disease in diabetic patients in countries of the European Union up to 2025. Nephrol Dial Transplant. 2015;30 Suppl 4:iv113-iv118.

9. Babua C, Kalyesubula R, Okello E, et al. Pattern and presentation of cardiac diseases among patients with chronic kidney disease attending a national referral hospital in Uganda: a cross sectional study. $B M C$ Nephrol. 2015;16:126.

10. Matsushita K, Ballew SH, Coresh J. Influence of chronic kidney disease on cardiac structure and function. Curr Hypertens Rep. 2015;17(9):581.

11. Pluta A, Stróżecki P, Krintus M, Odrowąż-Sypniewska G, Manitius J. Left ventricular remodeling and arterial remodeling in patients with chronic kidney disease stage 1-3. Ren Fail. 2015;37(7): 1105-1110.

12. Charytan DM, Cinelli A, Zeisberg EM. Association of circulating angiogenesis inhibitors and asymmetric dimethyl arginine with coronary plaque burden. Fibrogenesis Tissue Repair. 2015;8:13.

13. Franczyk-Skóra B, Gluba-Brzózka A, Wranicz JK, Banach M, Olszewski R, Rysz J. Sudden cardiac death in CKD patients. Int Urol Nephrol. 2015;47(6):971-982.

14. Cernaro V, Trifirò G, Lorenzano G, Lucisano S, Buemi M, Santoro D. New therapeutic strategies under development to halt the progression of renal failure. Expert Opin Investig Drugs. 2014;23(5):693-709.

15. Cernaro V, Lacquaniti A, Buemi A, Lupica R, Buemi M. Does erythropoietin always win? Curr Med Chem. 2014;21(7):849-854.

16. Singh AK, Szczech L, Tang KL, et al. CHOIR Investigators. Correction of anemia with epoetin alfa in chronic kidney disease. $N$ Engl J Med. 2006;355(20):2085-2098.

17. Pfeffer MA, Burdmann EA, Chen CY, et al. TREAT Investigators. A trial of darbepoetin alfa in type 2 diabetes and chronic kidney disease. $\mathrm{NEngl}$ J Med. 2009;361(21):2019-2032.

18. Buemi M, Campo S, Cernaro V, Donato V, Lacquaniti A. Erythropoietin and the truths of science. J Nephrol. 2011;24(5):564-568.

19. Moe S, Drüeke T, Cunningham J, et al. Kidney disease: Improving Global Outcomes (KDIGO). Definition, evaluation, and classification of renal osteodystrophy: a position statement from Kidney Disease: Improving Global Outcomes (KDIGO). Kidney Int. 2006;69(11):1945-1953.

20. Nickolas TL, Jamal SA. Bone kidney interactions. Rev Endocr Metab Disord. 2015;16(2):157-163.

21. Koh N, Fujimori T, Nishiguchi S, et al. Severely reduced production of klotho in human chronic renal failure kidney. Biochem Biophys Res Commun. 2001;280(4):1015-1020.

22. Larsson T, Olauson H. Un rapido aggiornamento su FGF23 per il nefrologo clinico. [A brief update on FGF23 for the clinical nephrologist]. G Ital Nefrol. 2014;31(2). Italian.

23. Cernaro V, Santoro D, Lucisano S, Nicocia G, Lacquaniti A, Buemi M. The future of phosphate binders: a perspective on novel therapeutics. Expert Opin Investig Drugs. 2014;23(11):1459-1563.

24. Ezumba I, Quarles LD, Kovesdy CP. FGF23 e cuore. [FGF23 and the heart]. G Ital Nefrol. 2014;31(6). Italian.

25. Sultana J, Musazzi UM, Ingrasciotta Y, et al. Medication is an additional source of phosphate intake in chronic kidney disease patients. Nutr Metab Cardiovasc Dis. 2015;25(10):959-967.

26. Savica V, Calò LA, Monardo P, Santoro D, Bellinghieri G. Phosphate binders and management of hyperphosphataemia in end-stage renal disease. Nephrol Dial Transplant. 2006;21(8):2065-2068.

27. Locatelli F, Del Vecchio L, Violo L, Pontoriero G. Phosphate binders for the treatment of hyperphosphatemia in chronic kidney disease patients on dialysis: a comparison of safety profiles. Expert Opin Drug Saf. 2014;13(5):551-561.

28. Bellinghieri G, Santoro D, Savica V. Emerging drugs for hyperphosphatemia. Expert Opin Emerg Drugs. 2007;12(3):355-365. 
29. Liu L, Wang Y, Chen H, Zhu X, Zhou L, Yang Y. The effects of noncalcium-based phosphate binders versus calcium-based phosphate binders on cardiovascular calcification and bone remodeling among dialysis patients: a meta-analysis of randomized trials. Ren Fail. 2014;36(8):1244-1252.

30. Wang C, Liu X, Zhou Y, et al. New conclusions regarding comparison of sevelamer and calcium-based phosphate binders in coronary-artery calcification for dialysis patients: a meta-analysis of randomized controlled trials. PLoS One. 2015;10(7):e0133938.

31. Zhai CJ, Yang XW, Sun J, Wang R. Efficacy and safety of lanthanum carbonate versus calcium-based phosphate binders in patients with chronic kidney disease: a systematic review and meta-analysis. Int Urol Nephrol. 2015;47(3):527-535.

32. Coppolino G, Lucisano S, Rivoli L, et al. Sevalamer hydrochloride, sevelamer carbonate and lanthanum carbonate: in vitro and in vivo effects on gastric environment. Ther Apher Dial. 2015;19(5):471-476.

33. Zhang C, Wen J, Li Z, Fan J. Efficacy and safety of lanthanum carbonate on chronic kidney disease-mineral and bone disorder in dialysis patients: a systematic review. BMC Nephrol. 2013;14:226.

34. Makino M, Kawaguchi K, Shimojo H, Nakamura H, Nagasawa M, Kodama R. Extensive lanthanum deposition in the gastric mucosa: the first histopathological report. Pathol Int. 2015;65(1):33-37.

35. Haratake J, Yasunaga C, Ootani A, Shimajiri S, Matsuyama A, Hisaoka M. Peculiar histiocytic lesions with massive lanthanum deposition in dialysis patients treated with lanthanum carbonate. Am J Surg Pathol. 2015;39(6):767-771.

36. Zoccali C, Mallamaci F, Cannata-Andía J. Phosphate binders and clinical outcomes in patients with stage 5D chronic kidney disease. Semin Dial. 2015;28:587-593.

37. Wu-Wong JR, Mizobuchi M. Is there a need for new phosphate binders to treat phosphate imbalance associated with chronic kidney disease? Expert Opin Investig Drugs. 2014;23(11):1465-1475.

38. Ito K, Takeshima A, Shishido K, et al. Treatment of hyperphosphatemia with bixalomer in Japanese patients on long-term hemodialysis with gastrointestinal symptoms. Ther Apher Dial. 2014;18 Suppl 2:19-23.

39. Astellas Pharm Inc. Astellas Submits Supplemental New Drug Application for Kiklin ${ }^{\circledR}$ Capsules, a Treatment for Hyperphosphatemia, in Japan. Tokyo: Astellas Pharm Inc.; 2015. Available from: https://www.astellas.com/en/ corporate/news/pdf/150317_1_Eg.pdf. Accessed September 18, 2015.

40. Savica V, Calò LA, Caldarera R, et al. Phosphate salivary secretion in hemodialysis patients: implications for the treatment of hyperphosphatemia. Nephron Physiol. 2007;105(3):p52-p55.

41. Savica V, Calò LA, Monardo P, et al. Salivary phosphate-binding chewing gum reduces hyperphosphatemia in dialysis patients. $J \mathrm{Am} S o c$ Nephrol. 2009;20(3):639-644.

42. Block GA, Persky MS, Shamblin BM, et al. Effect of salivary phosphatebinding chewing gum on serum phosphate in chronic kidney disease. Nephron Clin Pract. 2013;123(1-2):93-101.

43. Schmid H, Lederer SR. Novel iron-containing phosphate binders for treatment of hyperphosphatemia. Expert Opin Pharmacother. 2015;16(14):2179-2191.

44. Moustafa M, Lehrner L, Al-Saghir F, et al. A randomized, double-blind, placebo-controlled, dose-ranging study using Genz-644470 and sevelamer carbonate in hyperphosphatemic chronic kidney disease patients on hemodialysis. Int J Nephrol Renovasc Dis. 2014;7:141-152.

45. Wilhelm M, Gaillard S, Rakov V, Funk F. The iron-based phosphate binder PA2 1 has potent phosphate binding capacity and minimal iron release across a physiological $\mathrm{pH}$ range in vitro. Clin Nephrol. 2014;81(4):251-258.

46. http://www.velphoro.us [homepage on the Internet]. Velphoro ${ }^{\circledR}$ (sucroferric oxyhydroxide) chewable tablets. Fresenius Medical Care North America; 2014. Available from: http://www.velphoro.us. Accessed September 20, 2015.
47. Shah HH, Hazzan AD, Fishbane S. Novel iron-based phosphate binders in patients with chronic kidney disease. Curr Opin Nephrol Hypertens. 2015;24(4):330-335.

48. Summary of product characteristics. Available from: http://www.ema. europa.eu/docs/en_GB/document_library/EPAR_-_Product_Information/human/002705/WC500175254.pdf. Accessed September 20, 2015 .

49. European Medicines Agency. Assessment report: Velphoro. London: European Medicines Agency; 2014. Available from: http://www.ema. europa.eu/docs/en_GB/document_library/EPAR_-_Public_assessment_ report/human/002705/WC500175257.pdf. Accessed September 20, 2015.

50. Greig SL, Plosker GL. Sucroferric oxyhydroxide: a review in hyperphosphataemia in chronic kidney disease patients undergoing dialysis. Drugs. 2015;75(5):533-542.

51. Cozzolino M, Funk F, Rakov V, Phan O, Teitelbaum I. Preclinical pharmacokinetics, pharmacodynamics and safety of sucroferric oxyhydroxide. Curr Drug Metab. 2014;15(10):953-965.

52. Chong E, Kalia V, Willsie S, Winkle P. Drug-drug interactions between sucroferric oxyhydroxide and losartan, furosemide, omeprazole, digoxin and warfarin in healthy subjects. J Nephrol. Epub 2014 Apr 4.

53. LABEL: VELPHORO- ferric oxyhydroxide tablet, chewable [webpage on the Internet]. Bethesda, MD: United States National Library of Medicine. Available from: http://dailymed.nlm.nih.gov/dailymed/ drugInfo.cfm?setid=237da26c-f38c-4faa-93ad-735e 71 c9d0c 1 . Accessed September 23, 2015.

54. Geisser P, Philipp E. PA21: a novel phosphate binder for the treatment of hyperphosphatemia in chronic kidney disease. Clin Nephrol. 2010;74(1):4-11.

55. Wüthrich RP, Chonchol M, Covic A, Gaillard S, Chong E, Tumlin JA. Randomized clinical trial of the iron-based phosphate binder PA21 in hemodialysis patients. Clin J Am Soc Nephrol. 2013;8(2):280-289.

56. Floege J, Covic AC, Ketteler M, et al. PA21 Study Group. A phase III study of the efficacy and safety of a novel iron-based phosphate binder in dialysis patients. Kidney Int. 2014;86(3):638-647.

57. Floege J, Covic AC, Ketteler M, et al. Long-term effects of the ironbased phosphate binder, sucroferric oxyhydroxide, in dialysis patients. Nephrol Dial Transplant. 2015;30(6):1037-1046.

58. Chiu YW, Teitelbaum I, Misra M, de Leon EM, Adzize T, Mehrotra R. Pill burden, adherence, hyperphosphatemia, and quality of life in maintenance dialysis patients. Clin J Am Soc Nephrol. 2009;4(6):1089-1096.

59. Phan O, Maillard M, Malluche HH, Stehle JC, Funk F, Burnier M. Effects of sucroferric oxyhydroxide compared to lanthanum carbonate and sevelamer carbonate on phosphate homeostasis and vascular calcifications in a rat model of chronic kidney failure. Biomed Res Int. 2015;2015:515606.

60. Braithwaite V, Prentice AM, Doherty C, Prentice A. FGF23 is correlated with iron status but not with inflammation and decreases after iron supplementation: a supplementation study. Int J Pediatr Endocrinol. 2012;2012(1):27.

61. Bhattacharyya N, Chong WH, Gafni RI, Collins MT. Fibroblast growth factor 23: state of the field and future directions. Trends Endocrinol Metab. 2012;23(12):610-618.

62. Deger SM, Erten Y, Pasaoglu OT, et al. The effects of iron on FGF23mediated Ca-P metabolism in CKD patients. Clin Exp Nephrol. 2013;17(3):416-423.

63. Bolignano D, Coppolino G, Romeo A, et al. Neutrophil gelatinaseassociated lipocalin (NGAL) reflects iron status in haemodialysis patients. Nephrol Dial Transplant. 2009;24(11):3398-3403.

64. Pai AB, Jang SM, Wegryzn N. Iron-based phosphate binders - a new element in management of hyperphosphatemia. Expert Opin Drug Metab Toxicol. 201516:1-13. 


\section{Publish your work in this journal}

The International Journal of Nephrology and Renovascular Disease is an international, peer-reviewed open-access journal focusing on the pathophysiology of the kidney and vascular supply. Epidemiology, screening, diagnosis, and treatment interventions are covered as well as basic science, biochemical and immunological studies. The journal welcomes original research, clinical studies, reviews \& evaluations, expert opinion and commentary, case reports and extended reports. The manuscript management system is completely online and includes a very quick and fair peerreview system, which is all easy to use. Visit http://www.dovepress.com/ testimonials.php to read real quotes from published authors.

Submit your manuscript here: http://www.dovepress.com/international-journal-of-nephrology-and-renovascular-disease-journal 